\title{
Building Writing Skills in English in Fifth Graders: Analysis of Strategies Based on Literature and Creativity
}

\author{
Fernando López Niño ${ }^{1} \&$ Martha Elizabeth Varón Páez ${ }^{1}$ \\ ${ }^{1}$ Universidad del Tolima, Colombia \\ Correspondence: Fernando López, Universidad del Tolima, Colombia. E-mail: zepol0395@hotmail.com
}

Received: June 29, 2018 Accepted: August 17, 2018 Online Published: August 19, 2018

doi: 10.5539/elt.v11n9p102 URL: http://doi.org/10.5539/elt.v11n9p102

\begin{abstract}
The present article is centered on the description and analysis of the process of action-research followed by a group of twenty eight fifth graders of primary level in a public school in Colombia who improved their writing ability in English as a Foreign Language through the application of several creativity writing strategies. Among those strategies we can count the use of acrostics, calligrams, comic strips and posters, connecting children with fiction and real information taken from subjects taught at school. This research was designed with the objective of developing writing skills in a creative way, based on qualitative and quantitative methods by using surveys, checklists, field notes and a final interview to collect data. Findings revealed that writing mistakes were diminished after each one of the sessions application. Additionally, children were motivated to write in English and to assume different positions about topics of their interest from the advantages provided from new knowledge acquired about diverse topics related to their lives.
\end{abstract}

Keywords: creativity, game theory, literature, writing, writing process

\section{Introduction}

Most of the times in Colombia, second language learning in children occurs mainly at school contexts. According to my experience as English teacher, children do not have chances to learn English other than the ones provided by school's time. However, despite the teachers' dedication which includes their own materials developed and a great amount of time spent on this learning process, the results are really poor. Under these circumstances, it is quite necessary to develop creative activities to develop writing skills in foreign language in public field. By means of skills creative activities children can explore their imagination throughout a diversity of experiences that contribute to improve their language proficiency and potentiate their understanding by creating connections with new interdisciplinary knowledge at school.

Although, writing is not an easy process for the majority of the students, it is essential to enhance writing and to look for non-traditional strategies in order to foster children's interest on producing texts. As a part of daily life, teachers can create connections between school and students' interests as way of taking advantage from their ages, in which children's imagination represents an important source to construct different texts at school and to develop their skills in a second language.

This study is defined as an action research. According to Burns, (2010) defines an Action-Research as "a self-reflective, systematic, participatory and critical approach to enquiry" (p. 2). It encloses four basic stages as the author proposes: Observe, reflect, plan and act. The main purpose of this study was to contribute to the development of writing skills in a public school with a group of fifth graders through the application of some creative strategies that allowed participants to enhance their written production and connect them with other subjects' topics. As a general literature review, some theories founded in Brams, (1992), Cassany, (1999), Harmer, (2004), Nesbitt, (2017), Vásquez, (1998), Bowkett and Hitchmann, (2016), Hennessey, (2015), and Wittgenstein, (1988) among others, supported this study in terms of writing, reading, creative strategies and literature.

\section{Problem Statement}

Teaching English to children is a challenge to every language teacher, especially when the conditions are not favorable in a context like Colombia, where the rate of language proficiency in English is low in most of the public schools. Bearing in mind that, teaching English to children or beginners should be an appealing process in 
which planning in creative ways is really essential to enhance children's production. In relation to students' written production where this study was applied, the circumstances are quite similar to the general panorama in Colombia, due the fact that to most of the students are rated in deficient language proficiency, especially in writing which is a skill that results highly important to achieve tasks at school.

For that reason, the application of this study contributed in local contexts to expand strategies of teaching in creative ways, in which literature components present an interesting scenario to foster children's imagination and to help them to develop their English skills. In academic contexts, this research might put in discussion teaching practices in public or private schools. Taking into account the above, a research question emerges from this issue:

How do literature strategies and creativity influence the development of the writing skills process in fifth graders in a public school?

\section{Literature Review}

\subsection{Writing and Writing Process}

Writing is an important part of daily life, and it is involved in many situations in which a series of symbols conveys meanings with several purposes. Klein $(1985$, p. 70$)$ defines writing as "the ability to put pen and paper to express ideas through symbols, in this way, representations on the paper will have meaning and content that could be communicated to other people by the writer". García (2003, p. 13) defines writing as the representation of words or ideas through images or signs on a paper or other type of support with a pencil or any other instrument. In addition, Cassany $(1999$, p. 24) claims that writing is a manifestation of human linguistic activity such as the conversation, monologue or, in a different level, gestures codes or Morse code.. Writing is a tool that keeps words and share knowledge through history. In addition, writing is the product of a complex brain process that involves many functions from individuals. According to Garcia (2003, p. 149) writing is the result of a brain activity that involves global functions closely related to each other, and it transmits familiar words from another person or the existential memory of oneself, by means of traces, as well as the ability to express ourselves through the narration. Writing as a process is linked to how the learners develop their language skills as it is possible to make language learning progress really evident when the writing production improves.

As it is argued by Harmer, (2004, p. 4), the writing process corresponds to a progression identified by him as the process wheel and it is marked by four basic stages: Planning, Drafting, Editing and Final Version. According to Harmer, (2004, p. 4), Planning, which is also called as pre-writing, is the stage where learners are encouraged to write by taking notes, writing ideas and collecting information through brainstorming or listing. When planning, writers have to think about three main issues as Harmer, (2004) argues. In the first place, they have to consider the purpose of their writing, secondly, writers have to think of the audience they are writing for, and thirdly, writers have to consider the content structure of-the-text. Drafting is the stage where the learner writes his/her ideas and thoughts on the paper and develops the outlining. During this step, the most important task consists on designing a draft of the general information. Structuring the text and considering grammar is not the emphasis at this stage. The next stage is Editing. For Harmer, (2004, p. 5), it occurs when writers check their own production in order to correct language use and the purpose of the text. This might be a feedback done by the teacher or by pairs. The last stage described by Harmer, $(2004$, p. 5) is the Final Version in which the writer produces the last version. Checking grammar and spelling accuracies, punctuation, and word choices usually becomes the main task to be done at this stage.

\subsection{Creative Writing}

Muñoz (2016, P. 34) states that creative writing is any type of writing that is outside the scheme that can impose its standard communicative uses. Despite this concept is associated with fantasy and fiction, it might have a contrast with writing at school, expanding written production toward other ways of assignments. Creative writing reveals routes towards the construction of different types of texts, depending on the objectives that are proposed. Jiménez, $(1998$, p. 11) states that this type of writing is an open path toward metaphors, fantasy, imagination, chaos and order, and therefore human creativity, at the same time, all this allows us to travel in other stages of thought to create products full of imagination and emotion.

According to Delmiro, (2002), creative writing is an invitation to observe the world from other views, to change the order of the words, to express feelings and ideas, in order to understand personal experiences (p. 9). In such a way, creative writing represents another perspective of writing, it contains not just important components of writing, but the chance of expressing throughout several elements of reality and fantasy, and this is a kind of catharsis, of removing negativity to breathe other winds. 
However, the idea of creative writing should foster children's background; it should inspire them to use their own experience to create and to convey themselves. Tolstoi, cited in Vygotsky, (1982, p. 61), says that what he did with children was to wake up manners of expressing their knowledge toward an unknown world, then he built, combined, inspired and stated topics and in this way, he focused on their creative activity. Then, the process of creative writing should be like a fabulous game, as children learn when they have fun; teachers can take advantage from that in order to potentiate their writing skills.

In contrast, children are less fanciful than adults, creativity is based on logical processes and the combination with previous experiences are the foundations of creative fantasy as Jiménez (1998, p. 35, p. 36) argues. Therefore, children need to feed their minds of a series of daily practices, in order to expand their knowledge and the recognition of the world, creating new memories and mixing elements to perceive different ways of the reality.

\subsection{Games and Literature as Strategies for Writing}

Games are essential for children. They learn more when the game is involved in learning. Games catch the children"s attention and offer interesting chances to create positive connections with subjects at school. Wittgenstein, (1988, p. 25) claims that language game is a whole consisting of the language and the actions with which it is intertwined. Whereby, the exchanging of interactions allows the negotiation of meanings in the classrooms through assignments. Moreover, Macías, (2003, p. 3) says that in the development of comprehension abilities, the game is necessary to sharpen children's sensitivity toward the language, as well as sounds, rhythms, senses, images and to allow the configuration of an aesthetic attitude regarding to texts and life itself. Additionally, Brams, (1992, p. 32) claims that "applications of game theory to the humanities have grown over the years in such disciplines as history, philosophy, religion, and linguistics". In this sense, game theory in union with literature permits a wide range of strategies to apply in classes.

Equally important, Alonso, Borja, and Ferrer, (2010) argue that literature is a cross-linking of multiple elements, which employ strong pressures in the valuation of works, their circulation, their power in the construction of imaginaries, the influence on the formation of individuals. This definition shows a broad range of characteristics, in which literature can be developed; hence, the use of literature elements in word games offers different manners of increasing writing. Likewise, Brams, (1992) states that "Novels, short stories, plays, opera librettos, a narrative poem- all have been subject to game theoretic exegesis"( p. 32), this allows connection between L2 and all other subjects at school. Consequently, word games and literature might contribute to progress in second language, and with the support of both elements, language proficiency might be more efficient and creative.

\subsection{Acrostics}

According to Guadalupe (2010, p. 21) "the acrostic term comes originally from the Greece terms "akros", which means "extreme" and stiches, which is "verse". With them, Guadalupe argued, we get the expression "extreme verse". Likewise, Nesbitt (2017) describes acrostics as a fun poetic way of writing; he says that anyone can write an acrostic, following simple steps such as: decide the topic, write the words vertically, and brainstorm to describe ideas, place words in lines and fill in the lines to create the poem. These stages help children to facilitate the creation of acrostics and to avoid feelings of frustration and anxiety when they are writing in second language in an easier way.

Acrostics allow designing simple or more complex texts, according to children's ages, language level or teachers' purposes. In other words, children can write from words to sentences in their mother tongue, or in another language to explore vocabulary or with the purpose of fostering written production. Acrostics might be used in ways where students feel motivated to write things that involve their likes and hobbies. As part of daily activities, children can start writing acrostics by using their own names to have fun and to recognize certain features from themselves or their personalities. In this way, the teacher can show writing as an appealing and creative process of practicing a second language and not only as a feature to test students.

\subsection{Calligrams}

Unlike acrostics, Vásquez, (1998) defines calligrams as literary texts in which the phonic elements of the language merge within a graphic design, whereby, calligrams in simple ways might be favorable to work with children, placed them in games and artistic tasks. Furthermore, Yardy, (2011) states that "calligrams are poems which, as the name suggests, are written in a shape which represents the subject of the poem". In this way, calligrams allow the students to work with a variety of elements by combining shapes which children find enjoyable as exercises, in which they can also explore writing from other forms and views. According to Vásquez, (1998) calligrams benefit the graphic organization of the linguistic material; thus, the phonic and 
graphic merge perfectly. That is the why calligrams might be helpful for children to organize their ideas in contrast with images to potentiate the students' writing skills.

\subsection{Comic Strips}

Marquez, (2007) states that, comic strip is a text that tells short stories and adventures by using illustrations. It has its origin from Egyptians that combined texts and images. In 1820, it was a popular way of social communication in France, and later in North America it was expanded through massive newspapers, books and magazines. Comic books combine the appeal of graphic stories with the sophisticated organizational elements of written narrative as Bowkett, and Hitchmann, (2016, p. 10) claim. Comic strips correspond to a huge tool to encourage children to write, by supporting their ideas with texts and images, besides, as the story is told as a sequence, the format facilitates children to write. According to Horton, (2016), writing in comics is about people's own original creations, which will be drawn by oneself or another artist. Thus, comics provide the chance of telling several stories, by using creativity. In addition, drawings and images permit complementing students' ideas to enrich their texts while having fun. As a matter of fact, comics can be included in regular classes, by creating connections between stories and school subjects like social sciences, biology, ethics, and languages. In this sense, comics are quite useful, supporting texts and images to express their ideas and to develop their skills in L2. Moreover, Bowkett \& Hitchmann, (2012, p. 11) recommend the use of comics in the classroom as an important element to enhance reading and writing, as a result, what they suggest is that comic book might be used as part of the teacher's toolbox to develop literacy both in terms of children's reading abilities and those of writing.

\subsection{Posters}

According to the Random House Webster's College Dictionary (1991), a poster is "placard or bill posted or intended for posting in a public place, as for advertising posters in classes are an effective way of encouraging students to write and to foster group work" (p. 1054), in terms of assignments. As Hennessey, (2015, p. 5) claims, posters have been used in the classroom, often as a substitute for a term paper. Despite the inclusion of posters in the classrooms, they are not something new, although, it might be useful in the sense of designing as another type of writing task instead of papers or traditional ways.

The most valuable feature of posters is the variety of possibilities to design them, and the advantages are remarkable as Hennessey, $(2015$, p. 5) stated, the benefits of posters assignment can be tied back to the three characteristics of a quality writing assignment discussed: feedback, recognition of the recursive writing process, and help with organizing ideas. These elements make posters an integral activity, where children have the opportunity to participate in effective use of the language, receiving feedback, taking artistic, linguistic elements and mixing them through meaningful tasks.

\section{Previous Studies}

In some previous studies, Akhter (2014) carried out a research called "The Effectiveness of Creative Writing in Language Learning: A Comparative Study between Bangla Medium and English Medium Elementary Level". The aim of this study was to find out the effectiveness of creative writing in language learning, and to make a comparison between Bangla and English medium. The findings showed that students of both medium like Creative writing classes and it influences their language learning positively and participants were more motivated to participate in creative tasks such as stories, poetry, picture describing, compositions and personal letters. Therefore, it can be said that Creative writing can be used as an effective language learning tool for teachers and students. This study contributed in my research as for the development of creative writing assignments that the students found interesting to work.

In addition, Tok, and Kandemir, (2014) developed an experimental study called "Effects of creative writing activities on students' achievement in writing, writing dispositions and attitude to English". This study investigated the effects of using creative writing activities on 7th grade students' achievement in writing skills, in an elementary school in the city center of Denizli, Turkey in 2013. The study group was consisted of 17 females and 14 males. The results of the study showed that the application of creative writing activities is effective in increasing 7th graders' writing development in English. Besides, it was also found that using creative writing activities had a positive effect on writing dispositions of 7th grade students. Based on these results, it can be suggested that creative writing activities can be used in elementary graders in the English course to increase students' achievement in writing skills and let them write more.

In the Colombian context, Avila, (2015) introduced a pedagogical intervention called "Creativity in the English class: Activities to promote EFL learning" that included a set of creative activities designed to improve the oral 
and written production of students in the English classroom. Eventually, they responded to the proposed methods positively and were more willing and motivated to participate in chain games, creative writing, and screenwriting exercises. The activities helped to develop the students' fluency in both oral and written production and improved their understanding of English grammar and structure. Likewise, in this study, developing writing in creative ways might influence children positively, in order to consolidate their language proficiency by using alternative strategies to promote writing and increase the production of texts at school from early ages.

\section{Methodology}

\subsection{Research Design}

According to Burns, (2010), expressed that participants are actors in the classroom, that is why, action research is conducted by teachers and for teachers whose final purposes is to improve new teaching practices in educational contexts. Therefore, teaching depends on an active community of teacher practice aimed at exploring, discovering, developing or monitoring changes to practice. Action research encloses four basic stages as Burns (2010) proposed: Observe, plan, act or implement and reflect.

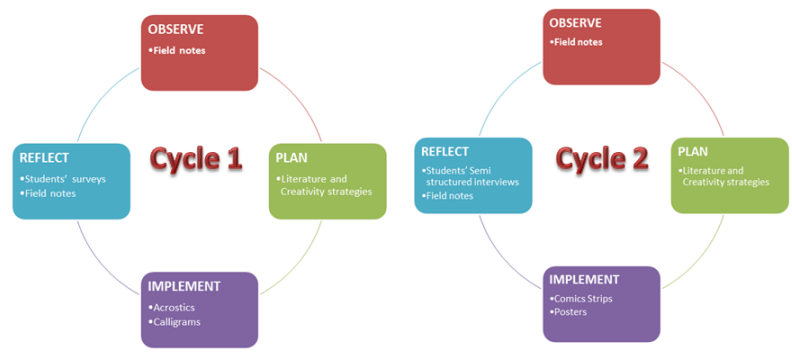

Figure 1. Research cycles (Burns, 2010)

\subsection{Qualitative and Quantitative Approach}

According to Crossman (2018) "qualitative research is a type of social science research that collects and works with non-numerical data and that seeks to interpret meaning from these data that help us understand social life through the study of targeted populations or places". As a purpose of this study, qualitative approach was quite relevant to describe behaviors and reactions, in which students expressed their preferences toward literature and creative tasks, and opinions about post activities. In addition, Crossman stated that "People often frame it in opposition to quantitative research, which uses numerical data to identify large-scale trends and employs statistical operations to determine causal and correlative relationships between variables". In this sense, quantitative approach, contributed to determine frequency students' mistakes, information about their likes for planning, and data to conclude about students' progress in terms of writing.

Likewise, Ashley, (2006) affirmed that "quantitative approach is associated with the rational and objective measurement of observable phenomena, while qualitative methodology focuses on assessment of subjective phenomena as ideas, opinion and pattern" (p. 70). The union of both approaches expanded the teacher's perspective in a wider outlook to collect and analyze data and to solve the research question, taking into account different variables regarding to observation and phenomena in the classroom. Being so, this study carried out 2 cycles of intervention upholding that, in the first cycle field notes were used to identify the problem and in the planning, some literature strategies were set to gather information in this first implementation. In the second cycle some more strategies were implemented taking into account the positive impact they had on the students' motivation and writing development. Subsequently, information was triangulated quantitatively and qualitatively with surveys and interviews instruments in order to answer the research question.

\subsection{Research Context and Participants}

This study was carried out in a police public school which was founded by a nun based on the catholic beliefs on September 17th of 1962. Currently, the school has 652 students from kindergarten to high-school; it is located in Ibagué city, Colombia. Additionally, the students selected from this school corresponded to a group of 28 children, sixteen girls and twelve boys aged between 10-11 years old with low average proficiency in English, the classes were given from Tuesday to Thursday an hour a day and Friday two hours. The whole group was selected in order to apply a series of strategies and to analyze their impact on their performance in writing in 
English language. The implementation of the strategies took the whole scholar year from February to November of 2017.

\subsection{Data Collection Instruments}

This section describes the instruments used to collect data in this research. Surveys, field notes, interviews and checklists were the instruments designed and used for this project. They were chosen as a valuable way of gathering data in relation to the learning process of writing but also in relation to the behaviors, the experiences and the reactions of the participants during the application of this study.

One of the instruments designed for this research was the survey as way to collect information about the influence of the strategies implemented with the students' writing skills. That is why, according to McClosky, (1969) argued that the survey corresponds to "any procedure in which data are systematically collected from a population or a sample thereof through some form or direct solicitation, such as face to face interviews, telephone interviews or mail questionnaires" (p. 34). According to (Mathers \& Fox, 2007) expressed that "a survey is a flexible research approach used to investigate a wide range of topics" (p. 4). Surveys often employ the questionnaire as a tool for data collection. In this sense, surveys are used to collect specific information according to the researchers' purpose. In the case of this project, a survey was an essential instrument as initial stage to know students' likes regarding to writing activities. This survey used a liker-scale from 1 to 5 in which the students had to express their satisfaction level with the writing strategies considering that they did not enjoy it (1), little (2), they did (3), a lot (4) and they loved it (5).

Another important instrument for this research was the systematic gathering of information through field notes. According to Bogdan and Biklen (1982) who stated that, field notes usually consist of two broad kinds of writing: descriptive and reflective. Descriptive notes refers to those that are detailed and accurate descriptions of what the inquirer sees, hears, and experiences such as behaviors, actions and experiences. Detailed, concrete and vividly specific words should be used instead of abstract, superficial, summary, or evaluative language. Reflective notes reflect in researcher's personal account of what he/she is learning from the process. Burgess, (1991) claimed that "when observing a culture, setting, or social situation, field notes are created by the researcher to remember and record the behaviors, activities, events and other features of the setting being observed" (p. 194). Additionally, Burgess, (1991) affirmed that notes are meant to be read by the researcher to produce meaning and an understanding of the culture, social situation or phenomenon being studied.

However, the children's process was not only described by the researcher but also by the children themselves. Other important instruments for implementation were interviews as an instrument that helped understand and interpret the research question. According to Patton (2002) "interviews comprise a number of open-ended questions that result in responses that yield information about people experiences, perceptions, opinions, feelings, and knowledge" (p. 4). Interviews are quite useful to gather relevant information in qualitative method. Upcraft and Schuh (1996) claimed that open-ended questions can also be given to students at the conclusion of a program or an event to receive quick and immediate feedback of the process and experience. Upcraft and Schuh (1996), also stated that questions presented before, during, and after a program allow for an interactive experience and a means to monitor learning progress. As a way of knowing participant's reactions, the final semi structured interview was important to analyze their point of views in relation to post activities, regarding preferences and task difficulties.

Finally, the use of a checklist was also a very useful instrument to analyze the whole process. Brun, (2011), states that a checklist is a list of items you need to verify, check or inspect. Checklists are used in every imaginable field. In the case of the present research, the checklists were used to encourage or verify that a number of specific lines of inquiry, steps, or actions were done by the researchers. It is useful to collect information in different ways and several purposes. Athappily (1986, p. 28) argues that "ideally, a checklist used for testing purposes should take up the metric that is being applied, the measurement technique, and, most importantly, the related quality characteristic". Checklist in different purposes might verify, check, measure or evaluate aspects observed from the researcher"s perspective. It is a valuable instrument to gather data from observation.

\section{Data Analysis}

The following table shows the information after the application of a survey that demonstrated children's opinions in relation to fiction, reading and writing preferences. This survey was a guide for the activities that were proposed as the strategy to improve writing difficulties. This survey was previously piloted and then applied, giving the results presented in Table 1. 
Table 1. Students' survey responses

\begin{tabular}{llllll}
\hline Questions & $\begin{array}{l}\text { 1. I do not } \\
\text { enjoy it }\end{array}$ & $\begin{array}{l}\text { 2. I enjoy it a } \\
\text { little bit }\end{array}$ & $\begin{array}{l}\text { 3. I enjoy it } \\
\text { much }\end{array}$ & $\begin{array}{l}\text { 4. like too } \\
\text { me It fascinates }\end{array}$ \\
\hline $\begin{array}{l}\text { A. I enjoy reading fiction or } \\
\text { imaginary texts like short }\end{array}$ & & $4 \%$ & $18 \%$ & $17 \%$ & $61 \%$ \\
stories. & & & & \\
$\begin{array}{l}\text { B. I enjoy reading nonfiction } \\
\text { texts such as essays, } \\
\text { biographies or chronicles. }\end{array}$ & $64 \%$ & $9 \%$ & $13 \%$ & $0 \%$ \\
$\begin{array}{l}\text { C. I enjoy reading short texts } \\
\text { related to heroes and nature, } \\
\text { where positive messages are }\end{array}$ & $0 \%$ & $9 \%$ & $9 \%$ & $78 \%$ \\
included. & & & & \\
\hline $\begin{array}{l}\text { D. I enjoy writing short texts } \\
\text { such as acrostics, calligrams, } \\
\text { comics or posters. }\end{array}$ & $0 \%$ & $46 \%$ & $5 \%$ & $35 \%$ \\
\hline
\end{tabular}

\subsection{Cycle 1}

\subsubsection{Students' Surveys}

This survey was applied to 28 students in order to gather the students' perceptions on whether the students like the writing strategies or not. This instrument was designed in Spanish for better comprehension and at the same time the teacher-researcher reminded the students the differences of the writing strategies used in class so the learners could differentiate them.

The results of the previous survey showed the importance of taking into account the students' opinions during the planning phase. As a matter of fact, children's interest was placed in fantasy like poems, comics and short stories related to heroes, animals and fiction. Just one participant manifested not to like short stories.

As a result, after applying this survey, the data showed that the majority of the students $74 \%$ enjoyed reading fiction texts. Just one child manifested low interest on it, and many of them dislike nonfiction texts like biographies or summaries. Their interest was placed mainly on fairy tales. In addition, most of the students wanted to develop their writing skills as an important part of their lives. They claimed about the importance of writing to achieve the tasks at school, and as a way of growing in academic and daily life.

After the application of writing strategies, students' mistakes decreased substantially. Writing mistakes frequency was measured taking into account some aspects, such as spelling, grammar, vocabulary and punctuation. Figure 1 evidences participants' performance through the development of writing strategies. During the first cycle, it was evaluated aspects of spelling and vocabulary due to the nature of the first strategies implemented regarding the acrostics and the calligrams.

Table 2. Brief summary of teacher's field notes

\begin{tabular}{|c|c|c|c|}
\hline Strategy & Students' attitudes & Difficulties & Observations \\
\hline Acrostics & $\begin{array}{l}\text { Most of the students } \\
\text { presented } \\
\text { attitudes in relation to } \\
\text { acrostics }\end{array}$ & $\begin{array}{l}\text { Lack of vocabulary to } \\
\text { express some ideas }\end{array}$ & $\begin{array}{l}\text { The activity } \\
\text { enjoyable } \\
\text { appealing } \\
\text { participants }\end{array}$ \\
\hline Calligrams & $\begin{array}{l}\text { Most of the students } \\
\text { enjoyed working with } \\
\text { animals" shapes }\end{array}$ & $\begin{array}{l}\text { Lack of vocabulary such } \\
\text { as adjectives to describe } \\
\text { animals }\end{array}$ & $\begin{array}{l}\text { The activity was } \\
\text { attractive because of } \\
\text { the use of their favorite } \\
\text { animals }\end{array}$ \\
\hline
\end{tabular}




\begin{tabular}{llll}
\hline Comic strips & $\begin{array}{l}\text { Most of the children liked } \\
\text { creating their comics by main difficulty was to } \\
\text { using images and short } \\
\text { texts }\end{array}$ & $\begin{array}{l}\text { The activity } \\
\text { in terms of grammar }\end{array}$ & $\begin{array}{l}\text { contributed to write } \\
\text { longer texts by using } \\
\text { fiction and real } \\
\text { information }\end{array}$ \\
Posters & $\begin{array}{l}\text { Most of the participants } \\
\text { had encouraging attitudes } \\
\text { working in pairs }\end{array}$ & $\begin{array}{l}\text { The main difficulty was to } \\
\text { extract } \\
\text { information to design their activity helped } \\
\text { posters }\end{array}$ & $\begin{array}{l}\text { Thiting and speaking } \\
\text { skills when they } \\
\text { presented their posters }\end{array}$ \\
\hline
\end{tabular}

Furthermore, field notes were beneficial to observe the students' reactions in detail in relation to work with other kinds of tasks. It was a valuable source to describe their interest on participating more actively and to create connections with other subjects at school and rechecking contents and knowledge from Social Sciences, Spanish and Ethics.

6.2 Cycle 2

\subsubsection{Interviews}

Interviews are essential to know about participants' reactions. As a part of data collection instruments, an interview was piloted in order to gather information related to children's feelings and likes. After previous analysis, some responses emerged from those recordings, in which most of the students answered as "I liked", "I disliked" and "It was hard", "It was easy". Table 3 reveals interview responses

Table 3. The interview Responses

\begin{tabular}{|c|c|c|c|c|}
\hline Question & $\begin{array}{l}\text { 1. How do you feel } \\
\text { after working with } \\
\text { acrostics in English } \\
\text { class? }\end{array}$ & $\begin{array}{l}2 \text {.How do you feel } \\
\text { after working with } \\
\text { calligrams in English } \\
\text { class? }\end{array}$ & $\begin{array}{l}\text { 3. How do you feel } \\
\text { after working with } \\
\text { comic strips in English } \\
\text { class? }\end{array}$ & $\begin{array}{l}4 \text { How do you feel } \\
\text { after working with } \\
\text { posters in English } \\
\text { class? }\end{array}$ \\
\hline $\begin{array}{l}\text { a. I } \\
\text { disliked. }\end{array}$ & $3 \%$ & $1 \%$ & $1 \%$ & $6 \%$ \\
\hline $\begin{array}{l}\text { b. I I } \\
\text { liked }\end{array}$ & $97 \%$ & $99 \%$ & $99 \%$ & $94 \%$ \\
\hline $\begin{array}{l}\text { c. It } \\
\text { was hard }\end{array}$ & $13 \%$ & $5 \%$ & $10 \%$ & $2 \%$ \\
\hline $\begin{array}{l}\text { d. It } \\
\text { was easy }\end{array}$ & $87 \%$ & $95 \%$ & $90 \%$ & $98 \%$ \\
\hline
\end{tabular}

The interview responses (see Table 3) showed a high acceptance about task developed in class, more than 94\% (I liked) answered with positive responses in relation to activities in class. Just a minimum percentage of $6 \%$ manifested they disliked the activities for reasons such as difficulties to write some ideas or their worries in group work. Likewise, $87 \%$ of the participants expressed that tasks were easy to do, and $13 \%$ in lowest score argued they were not easy, but they enjoyed the process of creation.

Also, in order to measure the writing strategies, it was necessary to do it in the amount of mistakes which were calculated in relation to how often students failed in certain aspects of writing (spelling, grammar, vocabulary and punctuation). Through the development of the texts, the teacher-researcher counted the mistakes and summarized in total numbers the ones that represent mistakes decrease in the group of 28 participants. After the application of acrostics as initial point, the amount of mistakes was 997 , the second task was the creation of calligrams and the amount of mistakes was 910 , the third one was the design of comic strips and the amount of errors was 613, finally posters showed 254 mistakes. Figure 2 evidenced an important progress from the first strategy to the last one. Despite children's writing difficulties, this research contributed to develop certain English proficiency and participant's interest in creative writing (see Appendices A, B and C). 
Figure 2 evidences that during the application of the strategies, mistakes decreased from $28 \%$ to 14 . It showed participants' progress in terms of spelling, grammar, vocabulary and punctuation. Equally important, the amount of these tasks had a positive influence on students' attitudes: they felt more motivated to write and to express their ideas and concepts about the topics chosen.

\section{Mistakes rate}
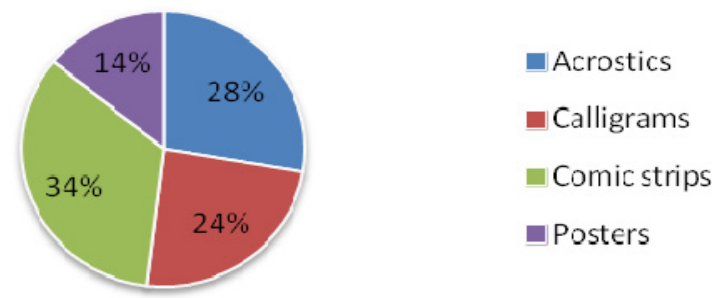

Figure 2. Mistakes rate

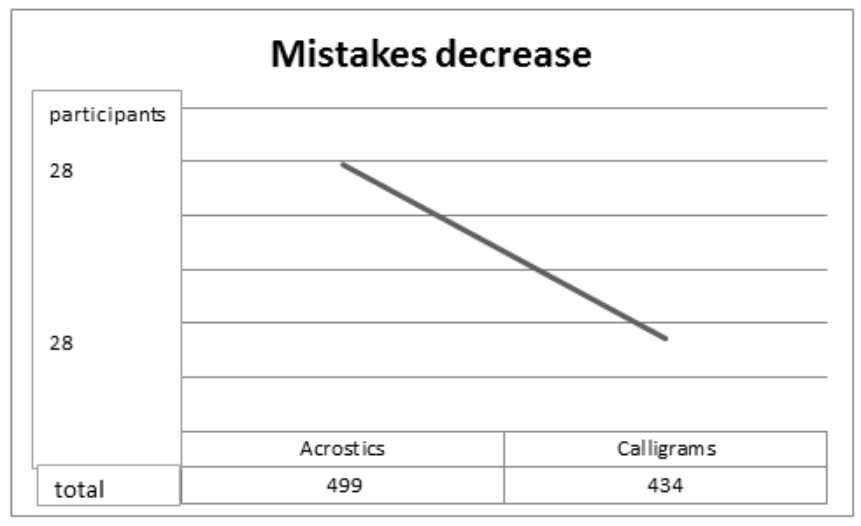

Figure 3. Total mistakes decrease

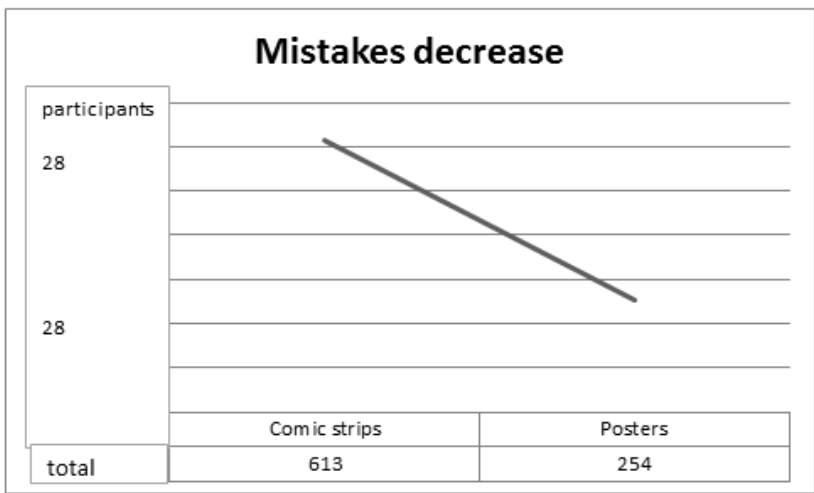

Figure 4. Total mistakes decrease

After the application of writing strategies, students' mistakes decrease substantially. Writing mistakes frequency was measured taking into account some aspects, such as spelling, grammar, vocabulary and punctuation. Figure 1 evidences participants' performance through the development of writing strategies.

In terms of mistakes decrease in comparison to the first strategy applied and the last one, the rate diminished from 499 to 254 mistakes in Figures 3and 4. It shows participants'progress regarding writing mistakes decrease with each one of the writing strategies used. Results showed that the strategies that had a bigger impact were Posters and Comic strips. Although, the surveys demonstrated that the acrostics and the calligrams also had a positive impact on their learning according to the students' perceptions. Besides, another important aspect to consider in the study is the implementation of the writing process in which evidences students progression gradually as they are more exposed to these types of strategies.

\section{Findings and Conclusions}

The findings in this research were divided into three categories: Survey results, the impact on English classes and the writing strategies.

\subsection{Survey Results}

First of all, survey results showed the importance of taking into account students' opinions while planning the process and the strategies for their own needs. As a matter of fact, children's interest was placed in fantasy like poems, comics and short stories related to heroes, animals and fiction; just one participant does not like short stories.

As a result, after applying this survey, data showed that the majority of the students enjoyed reading fiction texts, just one presented low interest on it, and many of them dislike nonfiction texts like biographies or summaries. Their interest was placed mainly on fairy tales. In addition, most of the students wanted to develop their writing skills, as an important part of their lives; they affirmed about the importance of writing to achieve the tasks at 
school, and as a way of growing in academic and daily life.

\subsection{The Impact on English Classes}

The impact of this study on English classes was encouraging, since children were more motivated to participate and to achieve the assignments. The way the teacher applied the activities were in progression, from the simple to the complex, in order to avoid feelings of frustration in L2. In like manner, children worked individually and in group work to have the chance of sharing ideas (see Appendices B).

The application of this study had an impact not just on the English classes, but, in other subjects, since the use of L2, allowed creating connections with topics related to everydayness at school such as the colonial times, the independence day of Colombia, Halloween as an international celebration, calligrams and comics used in Spanish classes as well, being calligrams part of the regular curriculum.

English might be seen as an integral part of education at this school, and not like an isolated subject, in which children use L2 just in English classes. The opportunity to create links between L2 and other subjects is really remarkable, this type of proposal points out to take an advantage from daily factors in a public school and to potentiate them toward bilingual education and creative thinking.

\subsection{Writing Strategies}

Writing strategies were planned taking into account not only the survey results but the analysis of needs which resulted from the diagnosis in the previous phase of the research. This data showed students' interest in particular elements of writing. First, acrostics were a starting point to foster writing as a creative task, in this stage students were exploring about themselves, adjectives, likes and nature, whereby, tension and stress were diminished by another way of writing. Despite the grammatical mistakes, children had fun and the written production increased and improved. In terms of the children's participation and the practice of L2, the effect was very positive. Second, calligrams provided the children an innovative manner of writing; they enjoyed choosing topics and planning their texts, following the shapes and even, sharing their activities with their partners.

Another important strategy which was implemented to improve writing skills was the use of comics. They were useful to connect children with other subjects, like social sciences. In this way, students realized about the use English in real life situations such as racism or discrimination. Additionally, imagination was an essential element to create short stories. Equally, the images provided by the teacher contributed to support their ideas through the texts, likewise, comics' format helped students to organize their texts in squares, where the story was told as a sequence and it was easier to write for children throughout speech bubbles.

The fourth strategy used was the posters. They enhanced writing from another perspective, in this stage, children worked in groups, in order to share their ideas and to involve them in the assignments. As a group work activity, children reflected about discrimination and shared views among boys' and girls' differences and commonalities, as part of planning their advertisements, they expressed their feelings about gender equality throughout their posters designs. Therefore, I agree with Macias, (2003) who considered that these games are necessary to sharpen children's sensitivity. This task was enjoyable for children, by using their own materials and images, as a matter of fact; the objective of working with others was enrichment in terms of writing. Being so, it is important to mention that this strategy had a relevant impact due to the students had the opportunity to increase their writing skills by elaborating more well-written compositions with appropriate mechanics and coherence.

\section{Implications of the Study}

This study gathered relevant information in terms of writing and the application of creative strategies in the classroom. Firstly, the survey was really useful to know about children's likes regarding to reading and writing preferences. Secondly, the strategies applied by the teacher showed positive results in relation to students' progress in writing. In fact, participants improved their written production and the mistakes rate diminished substantially. On the other hand, children participated more actively in each one of the assignments, since they felt more motivated in developing these tasks in groups and individually. It allowed facing several challenges to achieve the assignments, since they should support each other, but in other times, they should perform on their own.

A very important conclusion is that definitely writing is a skill that can be developed from different creative ways as children enjoy games and use their imagination to contrast with reality. Writing might be a huge source to enhance writing. In addition, there are a lot of strategies and approaches to implement in English classes to foster their abilities in second language; literature game for example, constitutes a funny and creative part to motivate children to include other elements from writing and to connect them with other subjects at school. Despite textbooks help teachers to guide English classes, it is quite important to integrate ways of writing in 
which students have the chance of playing with literature elements and to learn having fun.

Finally, the extent of this study permitted the involvement of other views in relation to how English was perceived at this school. Findings were placed in discussion to include English in other classes and to create bilingual projects in which second language might have an important role, instead of being an isolated subject at school. This study evidenced that English is an essential part of education to develop linguistic abilities that correlates components of several subjects at school.

\section{Limitations of the Study}

Despite the purpose of this study was reached, there were some limitations during its application. First of all, the limited time (6 hours a week) to apply the strategies in the regular schedule, secondly, the population was small, taking into account that there were two fifth graders groups (a group of 30 students and another of 28 students) at this school to carry out this project and to gather data in a broader perspective. Finally, the complexity of connecting the strategies proposed with the regular English classes that the school demands. Due to planning starts from the beginning of the school year, lots of issues involved certain adjustments in terms of planning modification such as, time, topics, schedules and other teachers' collaboration.

\section{References}

Akhter, N. (2014). The Effectiveness of Creative Writing in Language Learning: A Comparative Study between Bangla Medium and English Medium Elementary Level. BRAC University, Bangladesh.

Alonso, A., Borja, M., \& Ferrer, Y. (2010). Los conceptos de literatura infantil y juvenil, su periodización y canon como problemas de la literatura colombiana (pp. 158-177). Estudios de Literatura Colombiana.

Anne, B. (2010). Doing action research in English language teaching: A guide for practitioners. New York: Routledge.

Ashley, P., \& Boyd, WE (2006).Quantitative and qualitative approaches to research in environmental management. Australasian Journal of Environmental Management, 13(2), 70-78. https://doi.org/10.1080/ 14486563.2006.10648674

Athappily, K., \& Galbreath, R. (1986). Practical methodology simplifies DSS software evaluation process. USA: ELSNET.

Avila, H. A. (2015). Creativity in the English class: Activities to promote EFL learning. HOW, 22(2), 91-103. https://doi.org/10.19183/how.22.2.141

Bogdan, R., \& Biklen, S. (1982). Qualitattive research for education: An introduction to theory and methods. Boston: Allyn and Bacon.

Bowkett, S., \& Hitchmann, T. (2016). La utilización del cómic para mejorar la expresión oral, la lectura y la escritura. Madrid: Ediciones Morata, S. L.

Brams, J. (1992). Game Theory and Literature. New York: New York University.

Burgess, R. (1991). Keeping field notes. London: Routledge.

Brun, J. (2011). What is a checklist? Retrieved from https://nimonik.com/2011/10/what-is-a-check

Cassany, D. (1999). Construir la escritura. Barcelona: Paidos.

Crossman, A. (2018). An Overview of Qualitative Research Methods. Retrieved from https://www.thoughtco.com/qualitative-research-methods-3026555

Delmiro, B. (2002). La escritura creativa en las aulas. Entorno a los talleres literarios. Barcelona: Editorial GRAÓ.

García, J. (2003). Educar Para Escribir. México: Editorial LIMUSA, S. A.

Guadalupe, R. (2010). Palabras Literarias. España. Editorial. OCTAEDRO.

Harmer, J. (2004). How to teach writing. UK: Longman.

Hennessey, J. (2015). The Poster as a Writing Assignment. Furman University: South Caroline.

Horton, S. (2016). Comics writing 101: getting started in sequential storytelling.

Jiménez, A. (1963). Psicología de la lectura. Puerto Rico: Universidad de Puerto Rico.

Jiménez, C. (1998). Escritura creativa. Experiencias disciplinarias. Pereira: Gráficas Olímpica.

Klein, M. (1985). English Language Teaching. New York: Mc Graw Hill Companies Inc. 
Macías, L. (2003). El juego como método para la enseñanza de la literatura a niños y jóvenes. Medellín: Biblioteca Publica Piloto.

Mathers, N., \& Fox, N. (2007). Surveys and Questionnaires. The NIHR RDS for the East Midlands. East Milands: UD.

McClosky, H. (1969). Political inquiry: the nature and uses of survey research. California: University of California.

Muñoz, A. (2016). ¿Qué es la escritura creativa? Cursos y talleres. Retrieved from https://centraldeescritura.com/blog/que-es-la-escritura-creativa/

Nesbitt, K. (2017). How to Write an Acrostic.

Patton, M. (2002). Qualitative research and evaluation methods. California: Sage Random House Webster"s College Dictionary. Toronto: Macgraw Hill Edition.

Renata, G. (2010). Guía para talleres de escritura creativa. Creación y planeación. Bogotá D.C: Taller de Edición Rocca S. A.

Scheuren, F. (2004). what is a survey.

Schuh, J., Upcraft, M., \& Associates. (2001). Assessment practice in student affairs: an application manual. San Francisco: Joessy-Bass.

Tok, S., \& Kandemir, A. (2014). Effects of creative writing activities on students' achievement in writing: dispositions and attitude to English. Procedia-Social and Behavioral Sciences, 174, 1635-162. https://doi.org/10.1016/j.sbspro.2015.01.815

Vásquez, C, (1998-1999). Huidobro y la creación textual: fundamento rítmico de los caligramas. Chile. Universidad de Chile.

Vygotsky, L. (1982). La imaginación y el Arte en la infancia. Madrid. Akai.

Wallace, M, (2000). Action research for language teachers. Cambridge University Press.

Wittgenstein, L. (1988). Los cuadernos azul y marrón (3rd ed.). Francisco Gracia Guillén, Madrid, Tecnos.

\section{Appendices}

Appendix A. Checklist frequency mistakes

\begin{tabular}{|c|c|c|c|c|c|}
\hline $\begin{array}{l}\text { Comic strips } \\
\text { (Draft and final text) }\end{array}$ & Spelling mistakes & Grammar mistakes & ocabulary mistakes & Punctuation mistakes & Total mistakes \\
\hline participant 1 & 8 & 5 & 3 & 4 & 20 \\
\hline participant 2 & 7 & 4 & 0 & 6 & 17 \\
\hline participant 3 & 9 & 5 & 6 & 6 & 26 \\
\hline participant 4 & 7 & 5 & 8 & 9 & 29 \\
\hline participant 5 & 3 & 2 & 1 & 4 & 10 \\
\hline participant 6 & 2 & 1 & 3 & 2 & 8 \\
\hline participant 7 & 0 & 3 & 2 & 4 & 9 \\
\hline participant 8 & 0 & 8 & 4 & 7 & 19 \\
\hline participant 9 & 1 & 3 & 5 & 6 & 15 \\
\hline participant 10 & 4 & 6 & 4 & 8 & 22 \\
\hline participant 11 & 5 & 7 & 5 & 6 & 23 \\
\hline participant 12 & 2 & 4 & 2 & 5 & 13 \\
\hline participant 13 & 2 & 5 & 3 & 4 & 14 \\
\hline participant 14 & 8 & 10 & 8 & 7 & 33 \\
\hline participant 15 & 6 & 8 & 6 & 9 & 29 \\
\hline participant 16 & 7 & 9 & 7 & 6 & 29 \\
\hline participant 17 & 9 & 11 & 9 & 8 & 37 \\
\hline participant 18 & 10 & 13 & 10 & 11 & 44 \\
\hline
\end{tabular}




\begin{tabular}{llllll}
\hline participant 19 & 4 & 6 & 5 & 8 & 23 \\
participant 20 & 2 & 4 & 2 & 5 & 13 \\
participant 21 & 5 & 7 & 5 & 6 & 23 \\
participant 22 & 3 & 5 & 3 & 7 & 18 \\
participant 23 & 9 & 7 & 4 & 8 & 28 \\
participant 24 & 8 & 9 & 6 & 4 & 27 \\
participant 25 & 12 & 10 & 6 & 4 & 32 \\
participant 26 & 1 & 3 & 3 & 2 & 9 \\
participant 27 & 6 & 8 & 5 & 7 & 26 \\
participant 28 & 8 & 6 & 2 & 1 & 17 \\
\hline
\end{tabular}

Appendix B. Students" writing production with Comic Strips

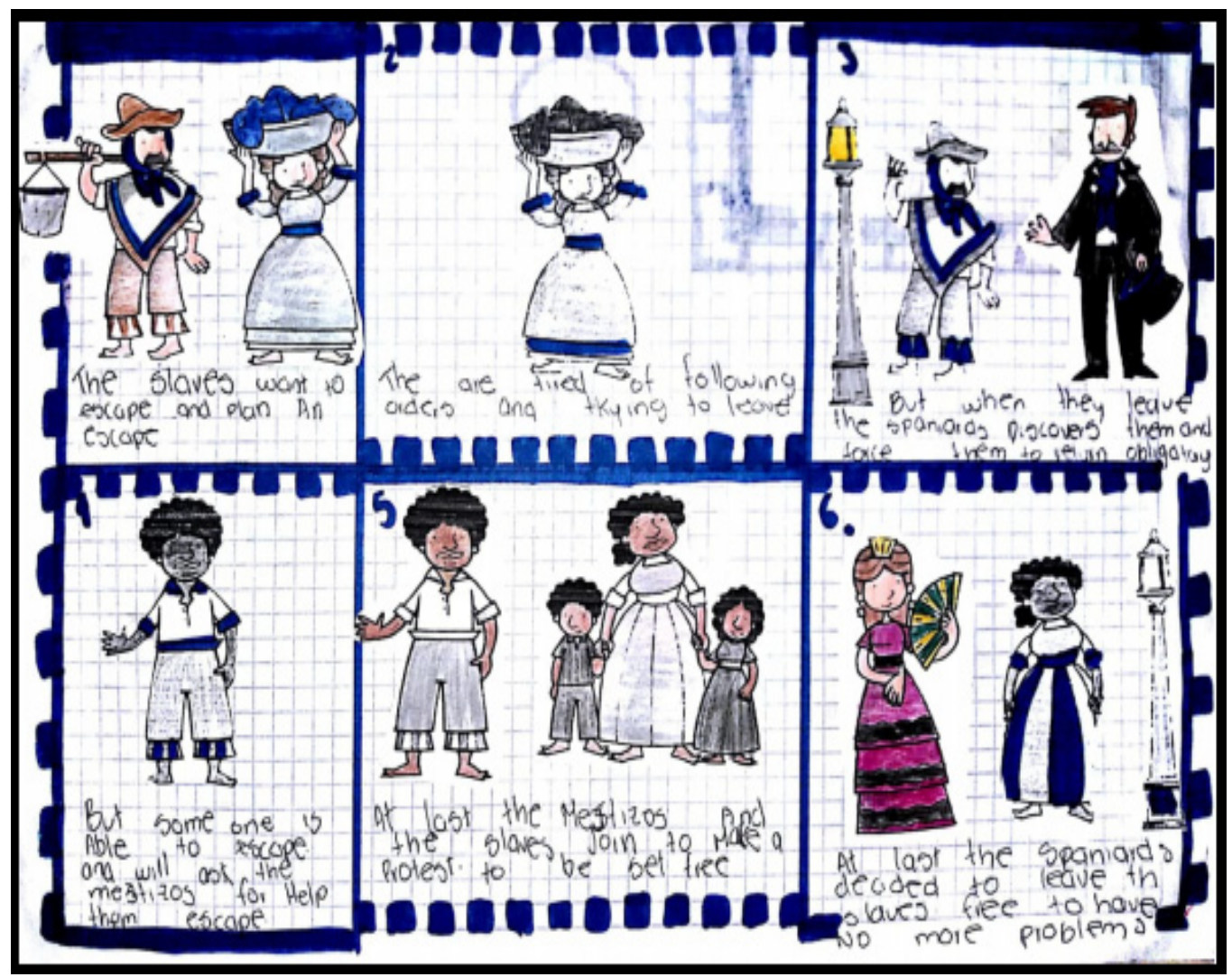




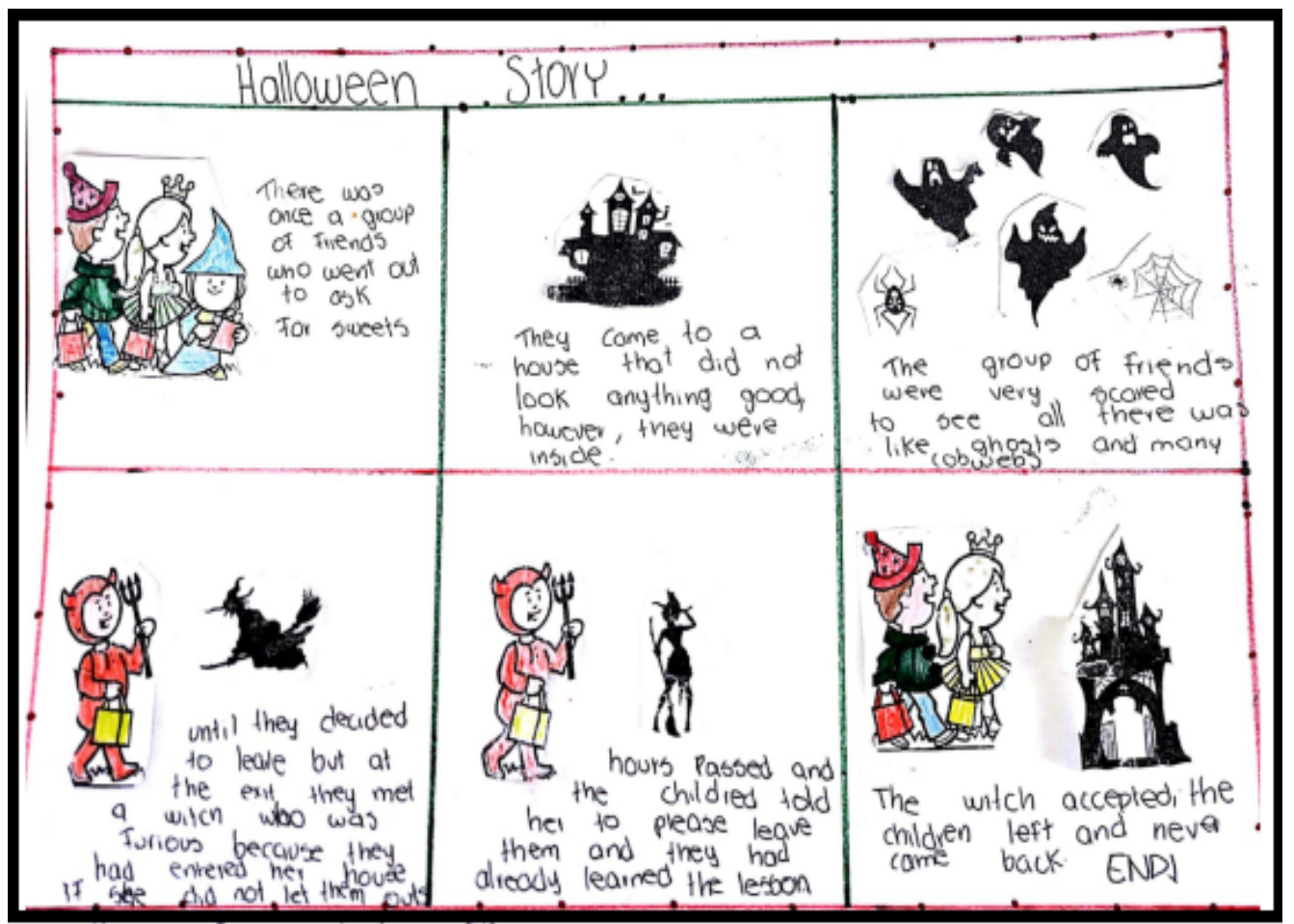

Appendix C. Students" writing production with Calligrams
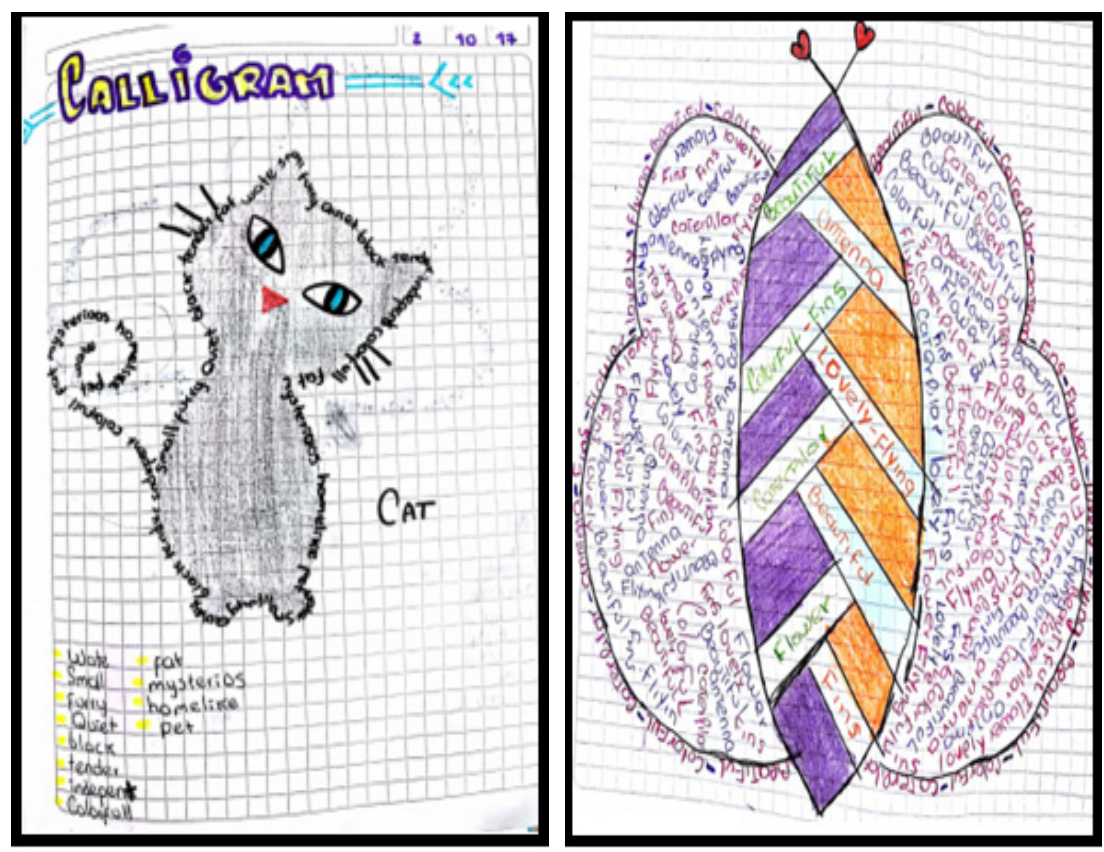


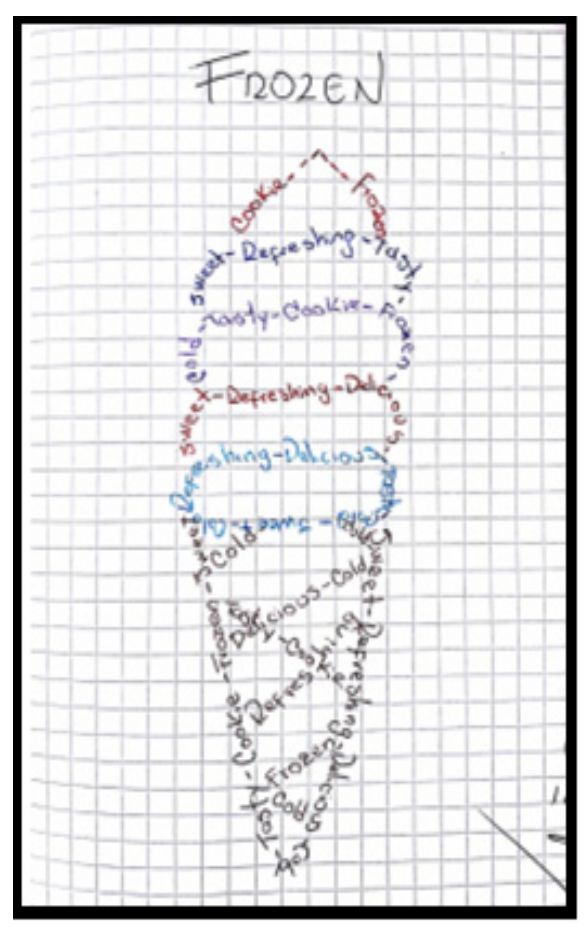

Appendix D. Students" writing production with posters

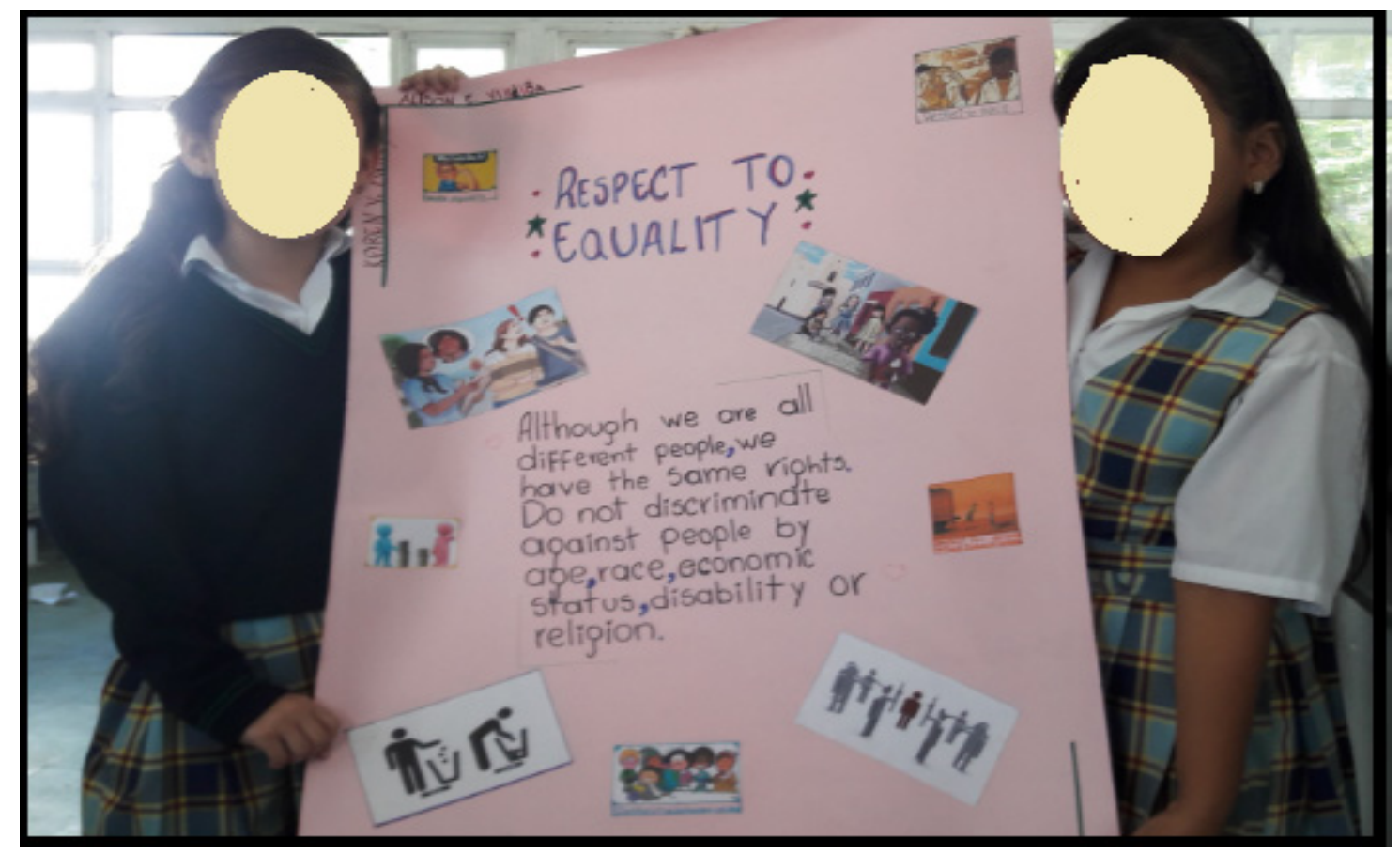




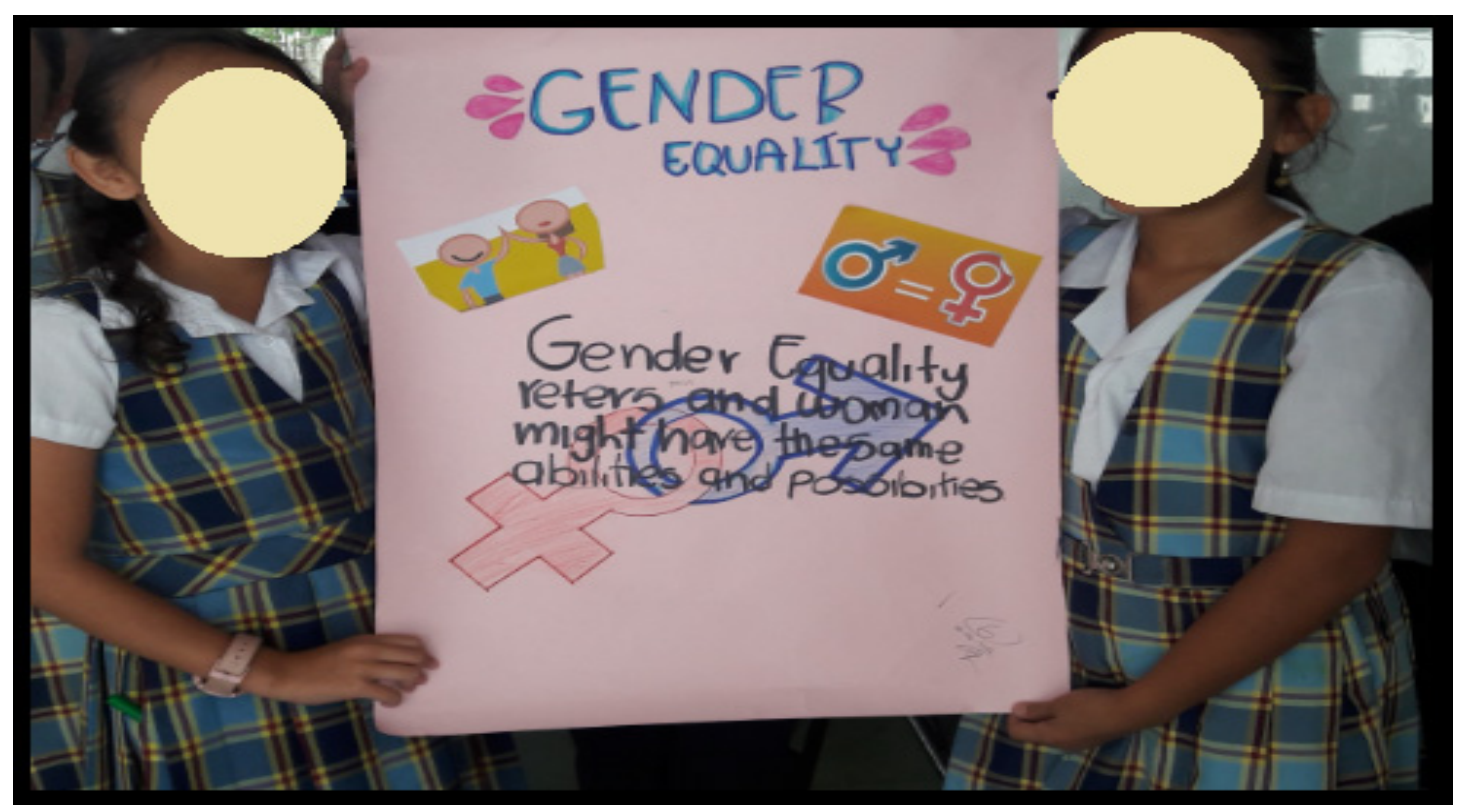

\section{Copyrights}

Copyright for this article is retained by the author(s), with first publication rights granted to the journal.

This is an open-access article distributed under the terms and conditions of the Creative Commons Attribution license (http://creativecommons.org/licenses/by/4.0/). 